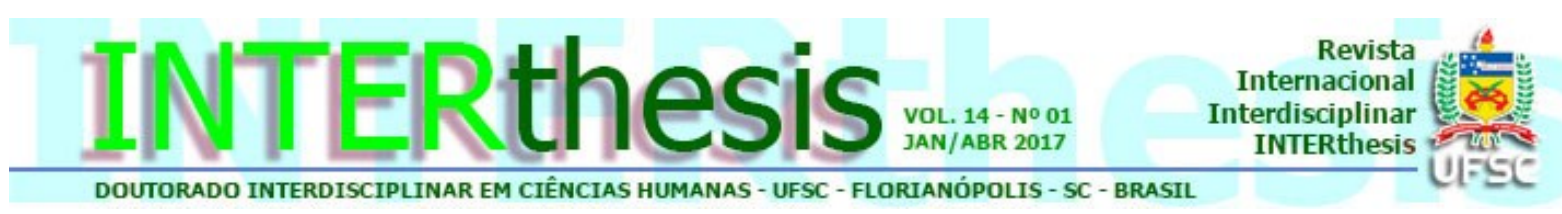

\title{
NOTAS SOBRE AS IMPLICAÇÕES PSICOSSOCIAIS DA VIOLÊNCIA NA BAIXA PROSTITUIÇÃO FEMININA NA CIDADE DE FORTALEZA/CE
}

\author{
Lorena Brito Silva ${ }^{1}$ \\ Verônica Morais Ximenes ${ }^{2}$
}

\section{Resumo}

Este artigo visa problematizar as implicações psicossociais da violência na baixa prostituição na cidade de Fortaleza/CE, buscando analisar as dinâmicas da violência e identificar suas expressões psicossociais no cotidiano das prostitutas. As violências contra prostitutas encontram-se veladas no universo da violência de gênero, reproduzindo a lógica de silenciamento que envolve a violência contra a mulher mesmo ocorrendo comumente no espaço público. A pesquisa teve uma perspectiva etnográfica, contou com a participação de 7 interlocutoras formais e utilizou a Análise de Conteúdo como referência. As análises apontam que a dinâmica da baixa prostituição é atravessada pelos arranjos territoriais, estando os códigos e regras da zona de prostituição em constante disputa com o território. A violência articula-se como uma teia relacional que acaba por impedir o reconhecimento do outro (classe, gênero ou raça/etnia) mediante o uso da força física e/ou simbólica, minando as possibilidades de diálogo, por um lado, e criando outros códigos, formas de interação e performances sociais, por outro.

Palavras-chave: Prostituição Feminina. Violência. Psicologia Social. Pobreza. Gênero.

\section{INTRODUÇÃO}

A expressão "a profissão mais antiga do mundo" comumente é utilizada para definir a prostituição. Contudo, todas as vezes que a escuto tenho a sensação de que, quase que compulsoriamente, ela associa uma mulher ao exercício de tal atividade, e mais que isso, uma mulher pobre (SILVA, 2014). A simbiose prostituição-prostituta é alimentada por relações desiguais de gênero e pela culpabilização da mulher por sua sexualidade, que camufla perfomances e formas diversas de organização (BARRETO, 2008). Piscitelli (2005) ao utilizar o termo "mercado do sexo", intencionalmente amplia o olhar para a lógica mercantil dos intercâmbios sexuais e econômicos da complexa rede de pessoas e instituições.

\footnotetext{
${ }^{1}$ Mestre em Psicologia pela Universidade Federal do Ceará, Fortaleza, CE. Psicóloga e educadora. Docência e pesquisa em Psicologia com ênfase em Psicologia Social, Psicologia Comunitária, Psicologia e Feminismo e Atenção Psicossocial em Sobral, CE, Brasil. E-mail: lorena.nessin@gmail.com

2 Doutora em Psicologia pela Universidad de Barcelona, Espanha. Pós-Doutorado em Psicologia da Universidade Federal do Rio Grande do Sul. Pesquisadora do CNPq. Professora da Universidade Federal do Ceará, Fortaleza, CE, Brasil E-mail: vemorais@yahoo.com.br
} 
Exercer a prostituição não é crime no código penal brasileiro, sendo proibido organizar comercialmente ou explorar pessoas, em concordância com o Tratado Abolicionista Internacional da ONU (1951). Uma das grandes problemáticas que cercam o debate sobre a prostituição no movimento feminista gira em torno da capacidade de exercer o direito sobre os próprios corpos (PISCITELLI, 2012).

Sobre isso, Wijeres (2004) aponta 4 regimes conceituais-jurídicos sobre a prostituição. Nas correntes proibicionistas e abolicionistas a prostituição é entendida como exploração, sendo no proibicionismo uma prática criminosa, devendo haver repressão e penalização aos envolvidos, e no abolicionismo a penalização seria apenas das situações de exploração. O regulamentarismo defende a organização e o controle sanitário e territorial por meio de ação policial, judicial e administrativa. No laboral quem exerce a prostituição é afirmado como trabalhador e busca-se a garantia de direitos sociais e trabalhistas. Os 3 primeiros eixos vitimam quem presta o serviço sexual ao não reconhecer sua capacidade de decidir sobre o corpo e a autonomia, e negam a prostituição como um trabalho sexual (PISCITELLI, 2005).

A partir de 2010, as vozes abolicionistas ganham maior visibilidade no feminismo do Brasil, principalmente com a institucionalização junto ao Estado, a presença de setores feministas em partidos políticos, a aproximação de movimentos transnacionais e o fortalecimento das "radfems". Se os argumentos estavam vinculados ao pecado e moralidade, agora associam a prostituição a violência sexista e a exploração sexual. Tal concepção vincula de modo perigoso, visto a imprecisão conceitual e legal, a prostituição com o turismo sexual e $\circ$ tráfico internacional de pessoas (PISCITELLI, 2014), alimentando a repressão e criminalização de quem exerce a prostituição.

A prostituição neste trabalho não é considerada sinônimo de violência. Ao problematizar as expressões da violência na prática prostitucional, busca-se visibilizar e ampliar os diálogos sobre as vulnerabilidades e as naturalizações, apontando a urgência do reconhecimento da prostituição como um trabalho, da garantia de direitos e de invenções de formas de cuidado. A violência contra prostituta se encontra velada no universo da violência de gênero, não existindo dados representativos no país. Mesmo quando ocorre em espaços públicos, reproduz a lógica de silenciamento que envolve a violência contra a mulher. 
Este artigo objetiva problematizar as implicações psicossociais da violência no contexto da baixa prostituição feminina, buscando analisar as dinâmicas de violências presentes e identificar suas expressões psicossociais e seus desdobramentos. É fruto de uma investigação realizada na Barra do Ceará (Fortaleza/Ceará). Metodologicamente teve inspiração etnográfica, mediante inserção comunitária entre 2012 e 2014, tendo como interlocutoras principais 7 mulheres.

\section{CONCEITUANDO A BAIXA PROSTITUIÇÃO FEMININA}

A compreensão da baixa prostituição passa pelo reconhecimento do território geográfico, político e existencial em que ela está inserida, em meio às redes de significado e aos modos de interação (SANTOS, 1977). As zonas de prostituição ou meretrício são áreas das cidades que se caracterizam como espaços de tolerância, invisíveis socialmente por estarem associados a ideias de pecado, de perigo e de sujeira e por agregarem diferentes perfis estigmatizados (BARRETO, 2008).

Historicamente, essas zonas se formam em regiões de baixa especulação imobiliária e/ou de abandono do Estado. Os códigos locais do território vão configurando o tipo de prostituição e a presença da atividade também caracteriza o território (SANTOS, 1997). Possuem acordos específicos e modificam-se a depender dos períodos do ano, dos turnos dos dias, das intervenções na cidade, visto que um território não acontece de modo estático, estando seus percursos desenhados em um terreno vivo e intenso de produção de subjetividades e expressão. Nesse sentido, podemos pensar o território enquanto produto de apropriação subjetiva e produção de signos, tendo um contorno singular de existência (ROLNIK, 2006).

Seus pontos majoritariamente ocupam espaços públicos (praças, pistões, esquinas, estações de trem, pontos de ônibus), e espaço privados como bares, pequenas bordéis, boates e casas de massagem, tendo normalmente parceria com motéis e quartos baratos para os programas. Ainda que haja uma exposição às dinâmicas da rua e do território, percebe-se um trânsito intenso entre espaços públicos e privados, e esta rotatividade revela uma busca de autocuidado, de sobrevivência e de segurança em seus cotidianos de batalha. Se de um lado, estar em locais privados implica perda financeira ou de autonomia diante da subjugação 
às regras dos espaços, por outro, a procura por espaços privados é uma pseudogarantia de proteção, diante da estrutura e dos responsáveis pelos estabelecimentos (SILVA, 2014). No território, enquanto arena de luta, há conflitos, jogos de força e diferentes modos de sociabilidade, sendo um lugar onde as relações de poder são mais instáveis e móveis e um campo de resistência (DELEUZE; GUATARRI, 1997).

Esse tipo de prostituição é caracterizado por uma rotina de muitos programas à baixos preços, uma carga elevada de trabalho, grande flexibilidade de horários e pontos e precárias condições de saúde e trabalho (insalubridade). Comumente há uma aproximação com disputas territoriais, com cenários de uso, abuso e comercialização de drogas, com pobreza e inúmeras privações.

A forma como tem sido pensada a relação da pobreza com a prostituição é delicada, pois comumente a privação financeira é entendida como causa ou justificativa para a prática da prostituição. Mayorga (2014) pontua uma espécie de pânico moral que envolve a necessidade dessa resposta social, situação que acaba por vitimizar os profissionais do sexo, negando a relação entre sexualidade e autonomia, reproduzindo assim desigualdades de gênero.

A problemática da relação prostituição-pobreza estaria na exposição e manutenção de uma maior privação de direitos sociais e na convivência com uma precarização das condições de desenvolvimento e possibilidades de gestão de suas vidas (NEPOMUCENO; SILVA; XIMENES, 2016). Em uma perspectiva multidimensional, a pobreza é entendida para além de determinantes econômicos, configurando-se por cadeias de miserabilidade que expõem os sujeitos a inúmeros riscos sociais diante das privações econômicas, sociais, educacionais, culturais e da saúde (CIDADE; MOURA JR.; XIMENES, 2012). O lugar de prostituta intersecta desigualdades de poder e experiências de preconceito e de resistências especificas (BARRETO, 2008; MAYORGA, 2014), que precisam ser articuladas as análises.

\section{CAMINHOS METODOLÓGICOS}

A investigação foi realizada com mulheres na Barra do Ceará, lugar que se tornou campo da pesquisa por congregar critérios acadêmicos, afetivos, simbólicos e operacionais (ANGROSINO, 2009). Este antigo bairro da cidade de Fortaleza passa despercebido em meio aos trânsitos turísticos da cidade. É um território 
estigmatizado pelos problemas sociais relacionados à pobreza e a disputa do tráfico de drogas, que possui uma zona de prostituição diversificada e antiga, com uma recente inserção de políticas públicas e caracterizado por um forte sentimento de apropriação e pertença (GÓIS, 2003) por parte dos moradores. No processo de construção de campo foi estabelecida parceria com Agentes Comunitários de Saúde de uma Unidade Básica de Saúde que facilitaram e mediaram a entrada no campo.

O caminho investigativo teve perspectiva etnográfica, deixando o campo e as relações "falarem", almejando uma progressiva aproximação e reconhecimento dos contextos, dos rituais, das relações, dos estranhamentos, que constituem os cotidianos de vida e trabalho. Como procedimentos metodológicos foram realizadas a observação participante (ANGROSINO, 2009), o diário de campo, a entrevista em profundidade e a técnica dos objetos geradores (RAMOS, 2004).

Durante a inserção de quase 1 ano e 6 meses de campo, 7 mulheres tornaram-se interlocutoras centrais ${ }^{3}$, sendo que 4 eram prostitutas, 2 eram proprietárias de casas de prostituição e 1 era agente comunitária de saúde. De acordo com a Tabela 1 é possível conhecer a caracterização das mulheres.

Tabela 1 - Principais interlocutoras da pesquisa.

\begin{tabular}{llc}
\hline Nome & Que faz/ Onde & Idade \\
\cline { 2 - 2 } & Prostituta em uma Casa de massagem da Barra & 36 \\
Nati & Garota de programa em uma boate da Praia de Iracema & 32 \\
Irene & Agente de saúde na Barra & 57 \\
Ana & Dona de Bar na Barra do Ceará & 68 \\
Luana & Prostituta e auxiliar de gerente em um casa na Barra do Ceará & 27 \\
Lu & Prostituta na avenida na praia na Barra e ex-gerente de bar. & 41 \\
Bia & Dona da casa de massagem e mãe de santo & 52 \\
\hline
\end{tabular}

Tais interlocuções possibilitaram a inserção simbólica e discursiva e a aproximação com as cenas de vida e trabalho. Dentre as principais contribuições, estão os diálogos sobre a vivência na prostituição, a história e a configuração da atividade no território, os aspectos econômicos, sociais, culturais do lugar.

\section{PARA PENSARMOS SOBRE A VIOLÊNCIA NA PROSTITUIÇÃO}

\footnotetext{
${ }^{3}$ Serão utilizados trechos de suas entrevistas realizadas na pesquisa aprovada no Comitê de Ética.

R. Inter. Interdisc. INTERthesis, Florianópolis, v.14, n.1, p.176-194 Jan.-Abr. 2017
} 
Diferente de outros cenários da prostituição, onde há um suposto anonimato, na baixa prostituição os desafios territoriais ultrapassam os limites laborais, impactando em outros aspectos de suas vidas. Para além de uma prática puramente comercial, existe uma trama de interações e mediações, revelando a criação de modos de vida (GÓIS, 2003), diante da apropriação e significação das atividades, dos lugares, das relações. Mais que fazer programas, elas vivem, constroem uma vida coletiva e individual, redes de cuidado, de celebração, de disputas, etc.

Suas histórias também trazem inúmeras violências. Piscitelli (2014) sinaliza a preocupação que pesquisadorxs trazem em falar sobre violações e serem associados com perspectivas abolicionistas, sendo um modo de enfrentamento posicionar-se a partir de outras leituras feministas. Visibilizar as questões apontadas pelas prostitutas sobre suas condições de trabalho, longe de vitimizá-las, é uma forma de confrontar os conservadorismos e moralismos vigentes e reafirmar a necessidade de avançamos nos direitos sociais, sexuais e trabalhistas.

A violência é perceptível nas dinâmicas dos programas (nos acordos sobre o ato sexual e o pagamento, as relação com as colegas), no processo de demarcação do território (entre rixas e parcerias), nas abordagens policiais, nas negociações com cafetões e traficantes e na discriminação pelo fato de serem prostitutas. Manifestase em "reiteradas arbitrariedades, detenções ilegais, surras e estupros, chegando a incorporar requintadas e brutais torturas" (PISCITELLI, 2014, p. 173).

Contudo, não vemos eco dessas violências nos discursos sobre violência contra a mulher, e nesse sentido, tantas outras violências não são facilmente identificadas ou questionadas (SILVA, 2014). À exemplo das violências de Estado que dificultam e/ou negam o acesso aos postos de saúde e de regulamentação da documentação, ou quando deslocam-se dos locais de moradia, camuflando suas identidades e ocupações. Também sofrem violências simbólicas na relação com os próprios movimentos ditos feministas, quando não são reconhecidas/ legitimadas nos espaços políticos ou respeitadas nos seus modos de viver e se relacionar com seus corpos (PISCITELLI, 2012).

Pinheiro (2006) pressupõe que as violências ou, como nomeou, processos de sociabilização mediado pela violência, atuam na constituição identitária das prostitutas, dando destaque a correlação entre e tempo de exposição/ convivência e os processos de naturalização. Ainda que a autora aponte que a prostituição traz 
em si estruturalmente traços e modalidades de violência, referindo-se à gênese da baixa-prostituição que remotam a França pós-revolução, é importante questionar tal engendramento. Uma entrevistada diz que a relação da prostituição com a violência

Raquel: [...]é uma coisa que por mais que se tente não tem como você está longe dela, pode até não acontecer, mas tá sempre ao seu lado. É isso. Caminha lado a lado com a gente. Pode ser a garota, pode ser o garoto. Qualquer pessoa que trabalha nessa forma caminha junto da violência, por isso é preciso evitar sempre essas situações.

Ela reflete sobre a vulnerabilidade e a convivência com situações que podem desencadear e agravar situações de violência, contudo, não se posiciona de modo determinista, considerando que pode ou não haver a ocorrência de violências a depender das zonas de fuga e/ou de cuidado que são construídas. As violências sofridas não são fruto da ocupação em si, tendo relação com a exclusão dessa categoria das legislações laborais específicas (BARRETO, 2008).

Mediante o uso da força física ou simbólica, a violência mina as possibilidades de diálogo, por um lado, criando outros códigos, formas de interação e performances, por outro. Longe de ser abstrata, é um fenômeno concreto e materializado no cotidiano, ainda que os seus aspectos simbólicos deem sentido à compreensão, sobretudo para quem a vive (PERES; RUOTTI; VICENTIN, 2010). Envolve tanto dimensões culturais e simbólicas da violência contra a mulher, como dimensões territoriais/urbanas e institucionais diante da invisibilidade por parte do Estado e da Sociedade Civil. Quando questionada sobre o significado da violência,

Luana: Nunca parei para pensar diretamente sobre isso... xô pensar... (pausa longa). Ah, só sei que me apavora! (risos) me apavora assim, por exemplo, uma coisa que a gente fica sozinha no quarto com o cliente. Até alguém ouvir e entrar para socorrer um monte de coisa acontece. Me apavora também porque eu já fui agredida.

Pensar sobre a faz sentir medo e insegurança. Esse pavor surge de aspectos extremamente concretos, ela está falando de uma situação que aconteceu e pode ocorrer novamente. É possível visualizar a articulação entre o simbólico e o concreto, onde de tão presente a situação passa a ter reverberações psíquicas, emocionais, e como em um ciclo dialético, as reverberações simbólicas têm traços concretos, reais - a faz pensar sobre as condições do trabalho. Assim, de tão materiais transformam-se em simbólicas, e de tão simbólicas materializam-se.

Martin-Baró (2003) compreende a violência como um movimento espiral, onde atos inicialmente isolados passam a ser justificados e legitimados a partir da condição que o outro é percebido/ reconhecido. Traz embutida em si aspectos R. Inter. Interdisc. INTERthesis, Florianópolis, v.14, n.1, p.176-194 Jan.-Abr. 2017 
ideológicos e raízes históricas, apresentando correlação com as estruturas sociais, os interesses pessoais e de classe de determinados grupos, estando o ato articulado com redes de significados e os jogos de poder (MARTINS; LACERDA JR, 2014).

Martín-Baró (2003) postulou três pressupostos para a compreensão da violências: 1) Apresenta múltiplas formas e possibilidades, escapando assim de simplificações destoantes; 2) Possui um caráter histórico, sendo impossível entendêla fora do contexto social onde se foi produzida; 3) Constitui-se com um aspecto espiral, onde os atos violentos são reconhecidos dentro de um processo autônomo e difuso, sem que necessariamente os desdobramentos tenham relação direta com o modo como se iniciou, ganhando novos formatos. Desse modo, deixa de ser pensada isoladamente, sendo assentada na lógica de institucionalização dos atos.

Dentre as violências presentes na baixa prostituição, destacamos para os objetivos aqui postos, as estruturais, resultantes do contexto de pobreza, e as culturais, que se desdobram dos eixos de subordinação machistas e sexistas.

\subsection{A VIOLÊNCIA ESTRUTURAL}

A violência tem sido banalizada diante do aumento de casos na esfera pública, e ao ultrapassar a esfera privada caí na lógica de um problema do outro, sendo pertinente compreendê-la enquanto um fenômeno criado e gestado socialmente (COSTA; PIMENTA, 2006). Minayo (2009, p.32) define violência estrutural como as "formas de manutenção das desigualdades sociais, culturais, de gênero, etárias e étnicas que produzem a miséria, a fome, e as várias formas de submissão e exploração de umas pessoas pelas outras".

Ela é produzida dentro de um sistema econômico e político, que reproduz vulnerabilidades e riscos sociais, entre elas, as relações violentas. O capitalismo, mais que um sistema econômico, é um regime civilizatório baseado na exploração da produção e na mercantilização das pessoas, do trabalho, da cultura. A desigualdade e a opressão são peças fundamentais para sua manutenção, estando à miséria, a pobreza e a violência marcando os cenários e as relações (NEPOMUCENO; SILVA; XIMENES, 2016). Entre as perversidades do sistema, estão as inúmeras tentativas de negação da pobreza, onde é depositado no sujeito a responsabilidade pela sua condição (CIDADE, MOURA JR; XIMENES, 2012).

Trazendo memória das andanças dissertativas, segue relato: 
Ana: [...] não entendo como essas mulher ganha tanto dinheiro e continua nessa mundiça, nessa pobreza sem tamanho, nessa sujeirada. Você vê aqui em casa como é, é simples mas é limpo, arrumadinho, vai lá onde elas dorme, é sujo, fede e não tem nada. Não tem roupa, não tem perfume, não tem nem lençol se eu não levar, e outra nem comida direito tem. Eu te pergunto, o que fazem com tanto dinheiro? Por dinheiro tem, afinal faz programa...Dou conselho, digo para pensarem no futuro, mas (...) nada.

$\mathrm{Na}$ "pobreza sem tamanho" há circulação de dinheiro, contudo isso não é suficiente para o bem viver. Convive-se com situações de miserabilidade, com a exclusão do sistema de saúde e educacional, com a restrição da circulação pelo bairro e pela cidade, com a desigualdade por conta das diferenças étnicas ou de gênero, com o distanciamento de atividades culturais, de lazer e sociabilidade, que afastam os sujeitos de condições saudáveis de desenvolvimento.

Auferir renda é importante, mas não é o bastante para minimizar as consequências da pobreza. Para Góis (2003), a condição de ser pobre impõe modos de vida, formas de aceitação e significação específicos, sendo que o estereótipo do pobre, perpetua situações opressivas e, conforme Freire (2004), apresenta como uma das principais armas na manutenção de dominação: o silenciamento. 0 individualismo alimenta a ideia de que o fracasso ou sucesso depende unicamente dos indivíduos, não sendo incoerente quando Ana deposita nas mulheres o insucesso para a transformação de suas realidades. Essa ideologia sustenta a naturalização da realidade, tomando fenômenos históricos como naturais (CIDADE, MOURA JR; XIMENES, 2012).

A população excluída dos privilégios do capital vive condições de alta vulnerabilidade, fato que tanto fortalece estruturalmente a violência, como a faz estratégia de enfrentamento contra a ordem social injusta (COSTA; PIMENTA, 2006). Assim, quando a zona se fecha em gueto, com regras e estratégias próprias, a violência surge como resistência diante de um processo desigual de exclusão. Bia, quando diz "aqui eu que resolvo" ou narra orgulhosa que "outro dia um cliente foi achar de cantar de galo com uma mulher, quando as outras se deram conta, lincharam ele lá mesmo", justifica o uso da agressão como uma resposta a ausência de oportunidades, de segurança, de cuidado, de saúde, por parte desta população.

\subsection{VIOLÊNCIA CULTURAL}

A violência cultural "se apresenta inicialmente sob a forma de discriminações e preconceitos que se transformam em verdadeiros mitos, prejudicando, oprimindo 
ou às vezes até eliminando os diferentes" (MINAYO, 2009, p. 36). Violências de gênero, racismo, xenofobia, intolerância religiosa são formas de sua expressão, visto que se fundam em relações desiguais de poder. Para seu entendimento é pertinente discutir algumas questões do feminismo.

O conceito de Gênero surgiu no campo acadêmico nos anos 1950/60, tornando-se central na ação política e nas teorias feministas na segunda metade do século XX (MAYORGA; COURA; MIRALLES; CUNHA, 2013). Mais que diferenças biológicas e naturais, ou fatores culturais de diferenciação, diz das relações de poder. É produzido na medida que é vivido e praticado cultural-politicamente, se forjando nos corpos, nas preferências, nas práticas discursivas, nas estéticas, nos prazeres (BUTLER, 2003; FOUCAULT, 1996).

É uma categoria importante na análise da falsa coerência entre sexo, gênero e desejo imposta pela heteronormatividade, que acaba por localizar os sujeitos em determinados lugares (BUTLER, 2003). É preciso prudência para escapar de usos totalizadores, reconhecendo outros marcadores sociais (raça/etnia, geração, classe, sexualidade) que atravessam as experiências dos sujeitos. As feministas negras e latino-americanas pautam essas questões no final de 1980, tencionando seus limites e seus efeitos normativos e reducionistas (MAYORGA, 2014).

A interseccionalidade (CRENSHAW, 2002) possibilita cruzar os marcados sociais e capturar as consequências das interações entre os eixos de subordinação (sexismo, patriarcalismo, racismo), superando a superposição das opressões ao analisar suas articulações. Abandona-se a visão das mulheres como um grupo homogêneo, analisando "os porquês" de algumas serem marginalizadas e estigmatiza e outras gozarem de benefícios e direitos, sendo um caminho potente para a análise das violências no cenário da baixa prostituição (MAYORGA, 2014).

A violência cultural alimenta o ciclo dominação-vitimização-reprodução, ao explorar, oprimir, silenciar, forjando-se nos processos de socialização. Lú afirma que "uma tapa é uma agressão tão séria quanto um palavrão mal dado ou uma peia daquelas. É uma coisa chata, e digo que todas já passou por algum caso, infelizmente". Para Saffioti (2014), não há nem mais e nem menos violência, pois, seu significado são definidos por quem está na relação. 
Ao refletirem sobre a postura dos clientes, Raquel acredita que eles se comportam como quem acreditam ter razão para abusar da força ou do poder, por estarem na condição de cliente e elas na de quem serve:

Raquel: o cliente se achou de pegar nas partes intimas da garota. Como ela não gostou e falou que não gostou, ele se achou no direito de tirar satisfação e partiu para cima com toda a força, parecia o dono da pista. Quer dizer, ele passa a mão, humilha e ainda quer bater e ela tem que aceitar, porque depois ele foi querer reclamar pra mãe [dona da casa], e ela cortou ele logo, dizendo: "quem manda aqui sou eu, fale baixo". Se ela tivesse em um outro local, na rua, por exemplo, sem segurança, sem nada, ela teria sido agredida mesmo, levado uma pisa dele. Ela não podia chamar uma polícia porque não podia dar em nada, já que com puta pode, ne?

$\mathrm{Na}$ relação cliente-prostituta, aparentemente, existe uma institucionalização do lugar da prostituta, nesse caso como um "objeto a ser tocado". Esse é um bom exemplo para exercitarmos o exercício proposto por Martín-Baró (2003), considerando a estrutura do ato, bem como o aspecto pessoal do agressor, o contexto e o fundo ideológico (MARTINS; LACERDA JR, 2014). O ato traz consigo uma série de elementos históricos e simbólicos sobre o que é permitido para a prostituta e para o cliente. Quando a situação é desnaturalizada, e ela não aceita ser tocada, o cliente utiliza a força para exercer sua vontade, e Raquel analisa que se a garota não estivesse sob o amparo da casa teria sido agredida e punida.

A institucionalização do lugar ocupado pela prostituta pode ser entendida pelo "estigma de puta", uma categoria moral de gênero que localiza a prostituta em um lugar de "desvio" ao escapar das normas instituídas pelo sistema sexo/ gênero (RUBIN, 2003; OLIVAR, 2012). Rubin (2003) definiu o sistema sexo/ gênero como as correlações estabelecidas entre o sexo e os conteúdos culturais de acordo com valores e hierarquias sociais, apontando que tal sistema produz como norma a divisão e hierarquização do sexo e da sexualidade, a desigualdade entre homens e mulheres e a heterossexualidade obrigatória e compulsória.

$E$ toda e qualquer mulher aprende cedo à não ser puta e, mesmo não sendo prostituta, é localizada nesse lugar quando quebra tais normas (OLIVAR, 2012). Quando ocupa o espaço público para lazer-prazer e não apenas para o trânsito referente ao trabalho ou as atividades sociais-familiares; quando age com autonomia em relação ao seu corpo e a sexualidade; quando sofre violência e é culpabilizada pela roupa, horário, localização.

Assim como é preciso garantir direitos ou tentar fortalecer a categoria profissional das prostitutas, é preciso mais para desconstruir o estigma de puta. Se 
não for central o entendimento da prostituição "enquanto direito sexual, que dialogue e se some às lutas por direitos fundamentais e por direitos laborais", pode-se reproduzir uma lógica que cria condicionalidades para sua aceitação: se for sustento e sacrifício seria trabalho, contudo, se for vulgaridade ou putaria já não haveria tolerância (OLIVAR, 2012, p. 100).

\section{IMPLICAÇÕES PSICOSSOCIAIS DA VIOLÊNCIA}

O ser humano se constitui historicamente em meio aos jogos relacionais, à apropriação dos instrumentos, à criação e compartilhamentos dos signos, aos processos de aprendizagem, à inserção cultural (VYGOTSKY, 2000). A cultura, enquanto mediadora dos modos de significação, marca as condições da vida social e a ação dos sujeitos, sendo o desenvolvimento psíquico atravessado pelo social e a realidade social pela ação do indivíduo (PINO, 2005).

A dimensão psicossocial diz dos processos de "atravessamentos do social no humano, assim como sua reversibilidade, do humano no social" (NEPOMUCENO, 2013, p. 58). O psicossocial está entre o pessoal e o coletivo, o familiar e o territorial, entre as formas de organização da zona de prostituição e o modo de trabalhar mais pessoal, deixando rastros nas visões de mundo, na capacidade de colaboração e socialização, na construção da autoimagem e nas estratégias de sobrevivência diante de próprias histórias, das dinâmicas da prostituição e do território.

Ainda que as mulheres compartilhem inúmeras situações na zona de prostituição, as implicações e compreensões desta vivência são profundamente particulares. De maneira inter-relacional, o sujeito apropria-se e internaliza os significados culturais de maneira particular, atribuindo interpretação pessoal as situações vividas (VYGOTSKY, 2000; NEPOMUCENO, 2013).

A violência marca os sentidos, significados, pensamentos, comportamentos e afetos singulares e coletivos, implicando nas compreensões particulares sobre sua presença e utilização enquanto modos de relação. Seriam as implicações psicossociais expressões do encontro dos significados coletivos e os sentidos pessoais sobre violência construídos por quem a vivencia, e também a pratica, a partir de sua imersão em uma dada cultura.

Em uma das entrevistas, Ana definiu a violência como "um ato de covardia, crueldade, é você usar de uma força com alguém que tá podendo menos ali, é um 
desrespeito sabe, bem forte, bem fundo. É desrespeito na alma, na pessoa mesmo, no eu". Ao relatar que viu muita gente "se diminuindo", diante da exposição e agressão sofrida, aponta para uma construção negativa da autoimagem. Esse "desrespeito da alma" seria a negação do outro e de sua capacidade de criação, sendo a violência um instrumento de manutenção do binômio dominação-opressão.

Freire (2004) problematiza o processo de coisificação da pessoa, que a impossibilita de criar, mudar, buscar, visto que "fere a ontológica e histórica vocação de ser mais" (FREIRE, 2004, p. 42). Seria assim a raiz da opressão, da exploração, do autoritarismo, revelando um abuso de poder e de força (simbólica, material, física, tecnológica, financeira) que lesa a vítima e à alteridade. Ana aponta que o fato das prostitutas conviverem com a violência, em diferentes situações, contribui para que se acostumem e passem a aceita-la. Quando há o que Ana chama de costume, estamos falando da captação dessa relação para si, para o seu autoconceito. A própria crença em si e em sua capacidade de agir é posta em jogo, estando o desrespeito da alma ocupando o lugar de acomodação diante da violência sofrida e a adoção do autoconceito negativo. A violência esvazia assim, as possibilidades de acordos sociais, ameaçando o diálogo, o respeito e o exercício da cidadania.

A partir das questões surgidas no contexto investigado, foram percebidas três principais dimensões das marcas ou expressões das implicações psicossociais. No nível territorial, as zonas de prostituição revelam tanto uma faceta protetiva, como restritiva, visto que diante da segregação das zonas e da estigmatização, suas vidas ficam reduzidas a esse lugar, contudo, elas reexistem ao criarem redes de cuidado e organização (ROLNIK, 2006), estando aqui as fontes dos apoios sociais e onde são construídas suas estratégias de enfrentamento.

No nível relacional, que possibilita uma compreensão do modo como as mulheres experienciam as relações, ora reativas e blindadas do contato com o outro, ora construindo relação de reconhecimento, diante da identificação com a vida, com o medo, com a dor e com a criatividade. As relações, assim como o território percorrido, vão ficando restritas a zona da prostituição. E no nível psicológico, que diz das imagens de si e dos afetos, percebe-se uma exposição continuada ao estresse, diversas reações emocionais e uma descrença, muitas vezes, da possibilidade de mudança, apresentando um acomodamento e naturalização, chegando a culpar-se pela situação vivida (CIDADE, MOURA JR.; XIMENES, 2012). 
A violência articula-se como uma teia relacional que impede o reconhecimento do outro, minando as possibilidades de diálogo, por um lado, e criando outros códigos, formas de interação e performances, por outro. A metáfora teia diz da articulação dialética da violência nos modos de viver das prostitutas no contexto de pobreza, como uma teia relacional e dinâmica, tecida por diferentes posicionamentos, olhares, conceitos, sentimentos, signos, em movimentos.

Os arranjos visualizados nesta rede seriam os significados sociais - as compreensões compartilhadas que contribuem nas leituras de mundo - e os sentidos - por serem a expressão das singularidades em meio as totalidades compartilhadas - alimentam essa rede, apresentando-se como os nós, que garantem sua sustentação desta rede (VYGOTSKY, 2000). Em contextos de vulnerabilidade está em jogo a cristalização desta rede, a captação de si por meio dos binômios de dominação e opressão que envolve a rede. Contudo, está nesses nós também a capacidade de desatar a rede, de possibilitar novas configurações, sendo esse desatar de nós da rede da violência os modos de enfrentamento, que ressurgem em meio as reproduções opressivas da violência.

\section{CONSIDERAÇÕES FINAIS}

Pensar a realidade das prostitutas pobres é reconhecer as diferentes facetas que as atravessam enquanto mulheres, pobres, putas, além de tantas outras singularidades pessoais e culturais. Zonas de prostituição, enquanto territórios de poder, prazer e vida, dizem das experiências vividas, sendo, simultaneamente, espaços de segregação/ marginalização e de sociabilidade/ proteção.

A violência enquanto um fenômeno complexo, dinâmico e transversal, surge no contexto prostitucional tanto como código de defesa, como de coersão, sendo legitimada e deixando rastros nas diferentes relações constituintes, reverberando em suas vidas ao ultrapassar a prática prostitucional. Articula-se como uma espécie de teia ou de rede, envolvendo códigos e signos culturais das dinâmicas laborais, territoriais, institucionais e estruturais, em planos micro e macrorelacionais, marcando a constituição de seu psiquismo, de suas relações, impondo lugares sociais a serem ocupados - ou esperando que as mesmas os ocupe.

Entre complexos jogos de saber e poder determinadas práticas e significados são adotados socialmente, regulando as relações e as formas de pensar, sentir, agir. 
A tolerância a sua presença é aumentada, e como Martin-Baró (2003) problematiza, em espiral, passa progressivamente a ter desdobramentos nas relações que estabelecem com outras pessoas, com o mundo e consigo mesmas.

Enquanto seguem invisíveis em direitos sociais e humanos, continuam expostas às vulnerabilidades e estigmatizações, diante das condições socioeconômicas desiguais, da convivência com as violências urbanas/territoriais e das naturalizações do machismo e da cultura de estupro que legitimam e silenciam as violações cotidianas. A naturalização da violência anestesia e passa a impedir o processo de conscientização das vivências opressoras, e pouco a pouco, silencia vozes e gestos, sendo necessário questionar e desconstruir compreensões cristalizadas, evidenciando sua construção social e histórica. 


\title{
NOTES ABOUT VIOLENCE IMPLICATIONS IN THE PSYCHOSOCIAL OF WOMEN'S PROSTITUTION IN FORTALEZA CITY
}

\begin{abstract}
This article aims to discuss the psychosocial implications of violence in the context of low prostitution in the city of Fortaleza (Ceará), by trying to analyse the dynamics of violence and identify the psychosocial expressions of violence in the daily life of prostitutes. Violence against prostitutes is veiled in the universe of gender violence, reproducing the silencing that involves violence against women even when it occurs in the public sphere. The research has an ethnographic perspective, with the participation of seven formal interlocutors, using the "Content Analysis" as reference. The analysis shows that the dynamics of low Prostitution is crossed by the territorial arrangements, with the codes and rules of a prostitution zone in constant dispute with the territory. Violence is structured as a relational web that seeks to prevent the recognition of the other (class, gender or race/ethnicity) through the use of physical and/or symbolic forces, undermining the possibilities of dialogue, on one hand, and creating other codes, forms of social interaction and performances, on the other.
\end{abstract}

Keywords: Women's Prostitution. Violence. Social Psychology. Poverty. Gender.

\section{NOTAS ACERCA DE LAS IMPLICACIONES PSICOSOCIALES DE LA VIOLENCIA EN CONTEXTO DE LA PROSTITUCIÓN FEMENINA EN LA CIUDAD DE FORTALEZA/CEARÁ.}

\section{Resumen}

Este artículo tiene como objetivo discutir las implicaciones psicosociales de la violencia en el contexto de la baja prostitución en la ciudad de Fortaleza, estado de Ceará, Brasil, tratando de analizar las dinámicas de la violencia e identificar sus expresiones psicosociales en la vida cotidiana de las prostitutas. Las violencias contra las prostitutas se encuentran veladas en el universo de la violencia de género, reproduciendo la lógica de silenciamiento que implica la violencia contra las mujeres incluso que ocurren comúnmente en el espacio público. La investigación tiene una perspectiva etnográfica, con la participación de 7 interlocutoras formales y utilizó el análisis de contenido como referencia. Los análisis muestran que la dinámica de baja prostitución es atravesada por los arreglos territoriales, con los códigos y normas de la zona de prostitución en constante disputa con el territorio. La violencia se estructura como una red relacional que busca impedir el reconocimiento del otro (clase, género o raza/origen étnico) a través del uso de la fuerza física y/o simbólica, impidiendo las posibilidades de diálogo, por una parte, y creando otros códigos, formas de interacción social y actuaciones, por el otro.

Palabras clave: Prostitución Femenina. Violencia. Psicología Social. Pobreza. Género. 


\section{REFERÊNCIAS}

ANGROSINO, M. Etnografia e Observação Participante. Porto Alegre: Artmed, 2009.

BARRETO, L. PROSTITUIÇÃO, GÊNERO E SEXUALIDADE: Hierarquias sociais e enfrentamento no contexto de Belo Horizonte. 2008. 154 f. Dissertação (Mestrado) Programa de Pós-graduação em Psicologia, Universidade Federal de Minas Gerais, Belo Horizonte, 2008.

BUTLER, J. Problemas de Gênero. Rio de Janeiro: Civilização Brasileira, 2003.

CIDADE; E. C.; MOURA JR., J. F.; XIMENES, V. M. Implicações psicológicas da pobreza na vida do povo latino-americano. Psicol. Argum., Curitiba, v. 30, n. 68, p. 87-98, jan./mar. 2012.

COSTA, M. R; PIMENTA, C. A. M. A violência: natural ou sociocultural?. São Paulo: Paulus, 2006.

CRENSHAW, K. Mapping the Margins: Intersectionality, Identity Politics, and Violence Against Women of Color. EM: FINEMAN, M; MYKITIUK, A. (Eds.). The Public Nature of Private Violence, New York: Routledge, p. 93-118, 1994.

DELEUZE, G.; GUATTARI, F. Acerca do Ritornelo. In: Mil platôs, capitalismo e esquizofrenia, v. 4. Rio de Janeiro: Ed34, p. 115-170, 1997.

FREIRE, P. Pedagogia do Oprimido. 41. ed. Rio de Janeiro: Paz e Terra, 2004.

FOUCAULT, M. A ordem do discurso: Aula inaugural no Collège de France, pronunciada em 2 de dezembro de 1970. São Paulo, Loyola, 1996.

GÓIS, C. W. L. Psicologia Comunitária no Ceará: uma caminhada. Fortaleza: Publicações Instituto Paulo Freire, 2003.

MARTIN-BARÓ, I. Poder, ideologia y violência. Madrid, Trotta, 2003.

MARTINS, K. O.; LACERDA JR., F. A Contribuição de Martín-Baró para o Estudo da Violência: uma apresentação. Revista Psicologia Política, São Paulo, v. 14. n. 31, p. 569-589, set./ dez. 2014. 
MAYORGA, C. A. B. Algumas contribuições do feminismo à Psicologia Social Comunitária. Athenea Digital, Barcelona, v. 14, n. 1, p. 221-236, mar. 2014.

MAYORGA, C.; COURA, A., MIRALLES, N., CUNHAM V. M. As críticas ao gênero e a pluralização do feminismo: colonialismo, racismo e política heterossexual. Estudos Feministas, Florianópolis, 21(2): 336, mai-ago. 2013.

MINAYO, M. C. S. Conceitos, teorias e tipologias de violência: a violência faz mal à saúde individual e coletiva. In: NJAINE, K.; et al. (Org.). Impactos da violência na saúde. Rio de janeiro: Fundação Oswaldo Cruz, 2009. p. 24-35.

NEPOMUCENO, B. B. Pobreza e saúde mental: uma análise psicossocial a partir da perspectiva de usuários do Centro de Atenção Psicossocial (CAPS). 2013. 151f. Dissertação (Mestrado), Programa de Pós-Graduação em Psicologia, Universidade Federal do Ceará, Fortaleza, 2013.

NEPOMUCENO, B. B.; SILVA, L. B.; XIMENES, V. M. Estratégias de enfrentamento à pobreza: uma análise a partir de estudos realizados com pessoas em sofrimentos psíquicos e com prostitutas. In: XIMENES, V.M. et al. (Org.), Implicações psicossociais da pobreza: diversidades e resistências. Fortaleza: Expressão gráfica e editora, 2016. p. 337-365.

OLIVAR, J. M. N. Prostituição feminina e direitos sexuais...diálogos possíveis? Sexualidad, Salud y Sociedad - Revista Latinoamericana, Rio de Janeiro, v. 11, p. 88 -121, ago. 2012.

PERES, M. F. T.; RUOTTI, C.; VICENTIN, D. Violência: Definição, tipos e representações. In WESRPHAL, M.F, et al. (Org.). Violência e juventude. São Paulo, SP: Hucitec, 2010. p. 40-58.

PINHEIRO, V. Socialização, violência e prostituição. 2006. 131f. Tese (Doutorado), Programa de pós-graduação em Educação, Universidade estadual de São Paulo, São Paulo, 2006.

PINO, A. As marcas do humano: às origens da constituição cultural e a criança na perspectiva de Lev. S. Vigotski. São Paulo, Cortez, 2005.

PISCITELLI, A. Apresentação: gênero no mercado do sexo. Cadernos Pagu, Florianópolis, v. 25, p. 7-23, jul/dez. 2005. 
Feminismos e Prostituição no Brasil: Uma Leitura a Partir da Antropologia Feminista. Cuadernos de Antropología Social, n. 36, p. 11-31, dez. 2012.

. Violências e afetos: intercâmbios sexuais e econômicos na (recente) produção antropológica realizada no Brasil. Cadernos Pagu, v. 42, p. 59-199, jan/jun. 2014.

RAMOS, F. R. L. A danação do objeto: o museu no ensino de história. Chapecó: Argos, 2004.

RODRIGUES, M. T. A prostituição no Brasil contemporâneo: um trabalho como outro qualquer? Rev. Katál. Florianópolis, v. 12, n. 1, p. 68-76, jan/jun. 2009.

ROLNIK, S. Cartografia sentimental: transformacoes contemporaneas do desejo. Porto Alegre: EdUFRGS, 2006.

RUBIN, G. Pensando sobre sexo: notas para uma teoria radical da política da sexualidade. Cadernos Pagu, Campinas, v. 21, p. 1-88, 2003.

SAFFIOTI, H. I. B. Gênero, patriarcado, violência. São Paulo: Função Perseu Abramo, 2004.

SANTOS, M. Espaço e Método. 4. ed. São Paulo: Nobel, 1997.

SILVA, L. B. IMPLICAÇÕES PSICOSSOCIAIS DA VIOLÊNCIA NOS MODOS DE VIDA DE PROSTITUTAS POBRES. 2014. 167f. Dissertação (Mestrado). Programa de pós-graduação em Psicologia, Universidade Federal do Ceará, Fortaleza, 2014.

VYGOTSKY, L. S. Manuscrito de 1929. Educ. Soc. [online], Campinas, v. 21, n. 71, p. 21-44, jul. 2000.

WIJERS, M. Delincuente, victima, mal social o mujer trabajadora: perspectivas legales sobre la prostitución. In: OSBORNE, R. (Ed.). Trabajadoras del sexo: derechos, migraciones y tráfico em el siglo XXI. Barcelona: Edicions Bellaterra, p. 209-221, 2004.

Artigo:

Recebido em 02 de Setembro de 2016. Aceito em 25 de Outubro de 2016. 